\title{
More than the sum of its parts? Assessing litter heterogeneity effects on the decomposition of litter mixtures through leaf chemistry
}

\author{
Natalia Pérez Harguindeguy • Cecilia M. Blundo • \\ Diego E. Gurvich • Sandra Díaz • Elvira Cuevas
}

Received: 22 May 2007 / Accepted: 20 November 2007 / Published online: 6 December 2007

(C) Springer Science + Business Media B.V. 2007

\begin{abstract}
Different components of functional biodiversity, such as functional type richness and composition, have been reported to affect the decomposition of litter mixtures. In spite of the numerous reports of these effects, mechanisms underlying patterns of decomposition in litter mixtures are still unclear. We analyzed whether mixture decomposition was affected by: (a) the number of species in the mixture (mixture richness); and (b) the mixture's functional composition (\% of fast- vs. slow-decomposing species included in the mixture). We then tested if variation between observed and expected values of decomposition in mixtures was associated to: (c) the initial
\end{abstract}

Responsible Editor: Alfonso Escudero.

N. Pérez Harguindeguy $(\bowtie) \cdot$ D. E. Gurvich · S. Díaz

Instituto Multidisciplinario de Biología

Vegetal (UNC-CONICET),

CC 495,

5000 Córdoba, Argentina

e-mail: nperez@com.uncor.edu

N. Pérez Harguindeguy • C. M. Blundo •

D. E. Gurvich · S. Díaz

FCEFyN, Universidad Nacional de Córdoba,

Vélez Sarsfield 299,

5000 Córdoba, Argentina

E. Cuevas

Instituto Venezolano de Investigaciones Científicas (IVIC),

Caracas, Venezuela litter characteristics of the component species (initial nitrogen, lignin, cellulose and hemicellulose content of litters); and (d) the chemical heterogeneity of the mixtures (variation in the same chemical compounds between the components in each mixture). When up to 5 species representing different functional types were included, both species richness and functional composition showed statistically significant non-additive, and in general positive, effects on litter mixture decomposition. The positive effect of mixture richness on decomposition did not disappear, but was much less marked, when considering mixture with slow-decomposing species only. Although the main driver of decomposition in a mixture is still the average decomposability of the component species (itself largely determined by litter quality), the species interactions in a mixture add a consistent source of variability that is worth considering when predicting the decomposability of a given mixture. We showed that a greater positive difference between observed decomposition rates and that expected from its component species alone was found in mixtures with higher mean nitrogen content and a higher heterogeneity in non-labile compounds. Our results offer quantitative proof that litter chemical heterogeneity, as well as the mean quality of the mixture, can affect the decomposability in litter mixtures.

Keywords Mass loss · Lignin - Litter interactions · Litter quality $\cdot$ Nitrogen $\cdot$ Richness 


\section{Introduction}

Despite the large amount of experimental work on the effects of species diversity on ecosystems processes (see Loreau et al. 2002 and Hooper et al. 2005 for review and synthesis), and the fact that most of net primary productivity enters the decomposition system as plant litter (McNaughton et al. 1989); there are comparatively few experimental studies that relate biodiversity with decomposition (Wardle et al. 1997, Hector et al. 2000, Hooper and Vitousek 1997, Smith and Bradford 2003, Gartner and Cardon 2004).

Experimental evidence suggests that in natural ecosystems, where several species grow and shed their litter in close temporal and spatial proximity, there are interactions between litters of different species decomposing together (Blair et al. 1990, McTiernan et al. 1997, Wardle et al. 1997, Hoorens et al. 2002, Smith and Bradford 2003, Gartner and Cardon 2004). As a consequence of these interactions, decomposition in litter mixtures can be different from that expected from the additive decomposition of component species in monocultures. Recent reviews indicate that synergistic interactions appear to be twice as frequent as antagonistic, whereas purely additive responses are more the exception than the rule (Gartner and Cardon 2004, Hättenschwiller et al. 2005).

In spite of the numerous reports of these interactions, mechanisms underlying patterns of decomposition in litter mixtures are still unclear. Several studies have rejected the role of simple measures of litter quality as a general predictor of litter-mixing interactions (Anderson and Hetherington 1999, Hoorens et al. 2003, Smith and Bradford 2003, Quested et al. 2005); however, the combination of more than one variable has not been explored so far. Moreover, the exploration of the chemical and physical heterogeneity among litter types within a mixture, and their interactions, has been indicated as a promising starting point towards a more mechanistic approach on the analysis of litter mixtures decomposition (Hättenschwiller et al. 2005). The rationale behind the heterogeneity in litter quality effect relates to a preferential exploitation of high-quality litter by decomposers that eventually leads to a high nutrient availability and allows nutrient transfer to the lowquality litter. This in turns leads to a more rapid decomposition of the more recalcitrant litter in the mixture. To date this hypothesis has only been tested in a small number of studies with contradictory results and its importance is difficult to assess (Hättenschwiller et al. 2005).

In this context, we aimed at analysing the influence of species mixtures richness and composition on its decomposition. We first tested whether mixture decomposition was indeed affected by: (a) the number of species in the mixture (mixture richness); and (b) the percentage of fast- versus slow-decomposing species (which we call functional composition hereafter). In order to explore mechanisms behind the effects of mixture on decomposition, we then tested if variation between observed and expected values were associated to: (c) the initial litter characteristics of the component species (initial nitrogen, lignin, cellulose and hemicellulose content of litters); and (d) the chemical heterogeneity of the mixtures (variation in the same chemical compounds between the components in each mixture).

\section{Materials and methods}

Study area

The decomposition experiment was carried out in Cuesta Blanca $\left(31^{\circ} 30^{\prime} \mathrm{S}, 64^{\circ} 35^{\prime} \mathrm{W}, 880 \mathrm{~m}\right.$. above sea level), in the Sierras de Córdoba Mountain range of central Argentina. The vegetation is a mixed xerophytic woodland (Zak and Cabido 2002). Mean annual precipitation is around $800 \mathrm{~mm}$, mainly concentrated in the warm season. Mean annual temperature is $15^{\circ} \mathrm{C}$ (De Fina 1992).

\section{Litter collection}

We selected 5 dominant species present in the study area, belonging to 5 contrasting plant functional types sensu Díaz and Cabido (1997): (L) Lithraea molleoides (Vell.) Engl. (evergreen tree; Anacardiaceae), (A) Acacia caven (Molina) Molina (nitrogen-fixing deciduous shrub; Fabaceae), (H) Hyptis mutabilis (Rich.) Briq. (perennial forb, Lamiaceae), (B) Bidens pilosa L. (annual forb; Asteraceae) and (S) Stipa eriosthachya H.B.K. (tussock grass, Poaceae). This experiment was not designed to separate the effects of taxonomic from functional diversity. The selection of one species for each functional type was carried out to maximize differences in decomposition between the 
components of the mixtures, and to cover a wider range of morpho-functional leaf attributes, which are known to be associated to different decomposition rates (Cornelissen 1996, Cornelissen et al. 1999, Pérez Harguindeguy et al. 2000, Vaieretti et al 2005). Between August and October 2000, we collected fresh leaf litter from at least 20 randomly selected healthy-looking adult individuals of each species in the study area.

\section{Litter decomposition experiment}

Litter samples were sorted and cleaned following Cornelissen (1996). Samples of air-dried litter (1 g) were weighed, and sealed into tube-shape nylon bags of $0.3 \mathrm{~mm}$ mesh size. Although this mesh size does not allow most of the macrofauna to contribute to the decomposition process, their effects are considered small compared with that of bacteria, protozoa, fungi and most of the micro and mesofauna (Cornelissen 1996, Pérez Harguindeguy et al. 2000). In order to convert air-dry mass of the samples before the burial to oven-dry mass, a sub-sample of each species was air-dried and subsequently oven-dried at $80^{\circ} \mathrm{C}$ for the assessment of water content.

We made all possible combinations of the selected species (mixtures of 2, 3, 4 and 5 species) and we incubated them in the field together with single species litterbags. For all mixtures we included the same quantity of species components up to a total weight of $1 \mathrm{~g}$. There were 20 replicates of each single species $(20$ reps $\times 5$ species $=100$ single species litterbags) and 8 replicates of each mixture ( 8 replicates $\times$ 26 different mixtures $=208$ mixture litterbags).

All litter samples were buried simultaneously in a purpose-built decomposition bed set-up where the litter itself was collected, during the rainy and hot austral summer (December 2000). Plants and roots were removed from the selected site, covering an area of approximately $4 \mathrm{~m}^{2}$. The samples were randomly and superficially buried under mixed soil and litter. To avoid damage by birds and mammals, the decomposition bed was covered with a plastic netting $(1 \mathrm{~cm}$ mesh size).

After 80 days of incubation $\left(21.5^{\circ} \mathrm{C}\right.$ mean air temperature and $488 \mathrm{~mm}$ precipitation during the period), the samples were unearthed and stored at $-14^{\circ} \mathrm{C}$. Once defrosted, adhering soil, soil fauna and other extraneous material were removed from the decomposing leaf litter by carefully brushing and swiftly rinsing with water. Litter samples were dried for $48 \mathrm{~h}$ at $80^{\circ} \mathrm{C}$ and weighed. Decomposition rate was defined as the percentage of litter weight loss after incubation.

This study was not intended to simulate in situ decomposition of each species or mixtures, neither to simulate the complexity of a natural litter layer. Standard conditions decomposition beds are designed to manipulate conditions, in our case functional composition and richness, and to explore possible mechanism operating behind the intricate decomposition process (Cornelissen 1996; Pérez Harguindeguy et al. 2000).

Litter chemical constituents

Samples of the same material used for decomposition was used to analyse the initial litter quality of the species and the mixtures. We measured nitrogen content using an Autoanalyser (RFA 300-Alpken, Wilsonville, OR, USA) and measured lignin, cellulose and hemicellulose contents following Goering and Van Soest (1970). From this data, we calculated the lignin/nitrogen ratio, a traditional indicator of litter quality (Cadisch and Giller 1997). We also calculated the total fibre content of the litter $(\mathrm{LCH}=$ lignin + cellulose + hemicellulose $)$ that, in a previous experiment (Vaieretti et al. 2005), was shown to be a powerful predictor of decomposition dynamics for the species considered in this study.

Data analyses

The expected decomposition in each mixture was estimated through averages of the component species decomposing in isolation (Wardle et al. 1997). These averages were calculated by randomly combining the values of decomposition for species decomposing in isolation (20 values per species, so the internal variation within species is taken into account). By doing this we obtained 20 expected values for each mixture, which we compared with the 8 observed values in the different statistical analyses performed.

ANOVA and a post-hoc test of Least-significant difference (LSD) were employed to test for significant difference between decomposition rates of single species, and between different mixtures. Based on the results of LSD of single-species litterbags, species were grouped in fast- or slow-decomposing. 
After all the analyses we checked normality and dispersion plots of residuals to test independence of errors and homogeneity of variance (Sokal and Rohlf 1995). All statistical analyses were carried out using InfoStat version 1.1 (InfoStat 2002).

\section{Effects of species richness and functional composition}

To explore the combined effect of mixture richness (number of species in the mixture) and functional composition (percentage of fast decomposing species in the mixture) we first performed a multiple regression to establish the percentage of the variance of mixtures decomposition rates explained by richness and functional composition. We later analysed the effects of richness and functional composition on decomposition rate by comparing, through a Student's t-test, the "observed decomposition" of mixtures (i.e., the one measured in the mixed litter bags), with the "expected value" of each mixture (calculated as a mean of the mass loss of all species included when decomposing in isolation, as indicated previously). Observed and expected decomposition rates (\% mass loss) of each mixture were compared using a standard t test for independent samples. Regression curves of observed and expected decomposition were obtained as functions of species richness and functional composition. Significant differences between the observed and expected regression curves were established by standard methods for slope and constants terms comparisons (Draper and Smith 1998).

\section{Effects of litter quality and heterogeneity in the mixtures}

The initial nutrient and fibre content of litter mixtures was calculated as the average of the initial nutrient and fibre contents of the species included in each mixture (Wardle et al. 1997). The initial nutrient and fibre contents of the mixtures were calculated to test the association between initial litter quality of the mixtures and their observed decomposition rates. We also calculated the coefficient of variation in initial nitrogen and in fibre contents (lignin, cellulose, hemicellulose and LCH). This coefficient is the difference of nitrogen or fibre content between species included in each mixture, and it is determined by dividing the standard deviation by the mean of the nitrogen or fibre contents of each of the constituent species in each mixture. As indicated by Wardle et al. (1997), this coefficient indicates the initial chemical heterogeneity of the mixtures. To search for a combination of initial litter quality variables to explain both mixtures decomposition and the difference between the observed and expected values we performed a backward stepwise regression procedure.

\section{Results}

When incubated in isolation, A. caven ( $\mathrm{N}$-fixing deciduous shrub) and B. pilosa (annual forb) decomposed significantly faster than L. molleoides (evergreen tree), H. mutabilis (perennial forb) and $S$. eriostachya (tussock grass) (Table 1). On this basis we defined two groups: fast-decomposing species (A. caven and B. pilosa) and slow-decomposing species (L. molleoides, H. mutabilis and S. eriostachya).

Mass loss in species mixtures tended to be higher than the expected values (based on the decomposition of the same species in isolation) mainly in 3 and 4 species mixtures. However, only 8 out of 26 mixtures showed statistically significant differences between observed and expected decomposition (Table 2). This is nevertheless higher than expected by chance (less than 2 mixtures). In all cases, these significant differences corresponded to observed values higher than expected values, that is, positive or synergistic effects.

The multiple regression performed to first explore the combined effect of mixture richness and functional composition showed that mixtures richness and mixtures composition ( $\%$ of fast species) explained $54 \%$ of the variance $(p=0.0001)$ on litter decay rate. Of this two factors functional composition alone explained $47 \%$ of the variance $(p=0.0001)$, while richness only explained $7 \%$ and was marginally significant $(p=0.08)$. As both coefficients were positive, and the two factors did not show a significant interaction, they indicate that percentage of fast species increased the decomposition of the mixture (as it can be expected) but increasing richness further increase these values.

Species richness effects on mixtures decomposition

When we averaged all mixtures with the same level of richness, the observed mean decomposition rates in mixtures with 3, 4 and 5 species were significantly 
Table 1 Litter initial quality and decomposition of dominant species belonging to different plant functional types in Cuesta Blanca, Argentina (standard errors for decomposition between brackets)

\begin{tabular}{llllll}
\hline & Nitrogen (\%) & Lignin (ppm) & Cellulose (ppm) & Hemicellulose (ppm) & Decomposition (\% dry mass loss) \\
\hline Acacia caven & 2.7 & 377 & 112 & 200 & $45.7^{\mathrm{a}}(9.9)$ \\
Bidens pilosa & 3.8 & 214 & 245 & 2.7 & $44.5^{\mathrm{a}}(11.7)$ \\
Hyptis mutabilis & 3.2 & 286 & 236 & 0 & $32.6^{\mathrm{b}}(5.1)$ \\
Lithraea molleoides & 1.7 & 221 & 99 & 124 & $32.0^{\mathrm{b}}(3.4)$ \\
Stipa eriosthachya & 1.7 & 131 & 427 & 270 & $27.7^{\mathrm{b}}(4.6)$ \\
\hline
\end{tabular}

Different upper-case letters indicate significant differences in decomposition between species $(p=0.05$; LSD Test)

higher than the expected values (Table 3). Additionally, observed decomposition significantly increased when the number of species in the mixture changed from 2 to 3 and 4 species, but 5 -species mixtures decomposed at the same rate than all other mixtures (Table 3). Confirming these results, the slope of the regression curve between the observed decomposition rates and species richness in the mixtures was significantly higher than the expected values (Fig. 1a; $p=0.03$ ).

Functional composition effects on mixture decomposition

In most of the mixtures where both slow and fast decomposing species were included, the observed decomposition of mixtures was higher than expected, despite the fact that they were significant only in 8 cases out of 21 . Litter mixtures containing only slow decomposing species (HL, HS, LS, HLS) also tended to decompose faster than expected, while the observed decomposition rates in mixtures containing only fast decomposing species (AB) tended to be lower than expected. However, none of these two trends were statistically significant (Table 2).

To summarize these results we tested the regression curves that better fitted the relationship between expected and observed decomposition with mixtures composition (\% of fast decomposing species included in the mixture). Unsurprisingly, this curve was a linear one for expected decomposition (adjusted $R^{2}=0.94, p=$ 0.0001 ), but for observed decomposition the better fit was a quadratic relationship (adjusted $R^{2}=0.53, p=$ 0.0001) (Fig. 2). Additionally, when predicted values and their confidence intervals were compared between the curves, they were significantly different only for intermediate values of mixture functional composition

Table 2 Expected (average of mass loss in monoculture) and observed mass losses values in mixtures (standard errors between brackets)

\begin{tabular}{|c|c|c|c|c|c|c|c|c|c|c|c|}
\hline \multicolumn{3}{|c|}{2 species mixtures } & \multicolumn{3}{|c|}{3 species mixtures } & \multicolumn{3}{|c|}{4 species mixtures } & \multicolumn{3}{|c|}{5 species mixture } \\
\hline & $\mathrm{E}$ & $\mathrm{O}$ & & $\mathrm{E}$ & $\mathrm{O}$ & & $\mathrm{E}$ & $\mathrm{O}$ & & $\mathrm{E}$ & $\mathrm{O}$ \\
\hline $\mathrm{AB}$ & $45.1(7.3)$ & $43.5(8.5)$ & $\mathrm{ABH}$ & $40.7(5.6)$ & $39.4(4.9)$ & ABHL & $38.7(4.2)$ & $41.5(5.3)$ & ABHLS & $36.5 *(3.6)$ & $39.0(3.1)$ \\
\hline $\mathrm{AH}$ & $38.9(5.2)$ & $40.5(4.1)$ & $\mathrm{ABL}$ & $40.9(5.1)$ & $43.7(7.4)$ & ABHS & $36.9^{\mathrm{ms}}(4.4)$ & $40.8(3.8)$ & & & \\
\hline $\mathrm{AL}$ & $38.2 *(4.9)$ & $44.7(4.6)$ & ABS & $39.3 *(5.1)$ & $42.3(2.2)$ & ABLS & $37.6(4.0)$ & $40.5(5.2)$ & & & \\
\hline AS & $36.7(5.9)$ & $37.9(2.3)$ & AHL & $36.8(3.4)$ & $35.2(9.2)$ & AHLS & $34.5^{*}(3.1)$ & $43.8(2.3)$ & & & \\
\hline $\mathrm{BH}$ & $38.2(7.3)$ & $35.9(5.2)$ & AHS & $35.1(4.2)$ & $35.6(2.8)$ & BHLS & $34.2(4.0)$ & $36.0(4.9)$ & & & \\
\hline BL & $38.5(6.4)$ & $38.0(6.3)$ & BHL & $36.4 *(5.2)$ & $41.4(4.9)$ & & & & & & \\
\hline BS & $36.1(5.9)$ & $38.2(3.9)$ & BHS & $34.7 *(5.0)$ & $39.2(3.9)$ & & & & & & \\
\hline HL & $32.3(3.0)$ & $33.4(4.5)$ & HLS & $30.8(2.7)$ & $32.4(4.2)$ & & & & & & \\
\hline HS & $29.8(3.8)$ & $30.3(4.2)$ & ALS & $35.3 *(3.9)$ & $38.7(1.6)$ & & & & & & \\
\hline LS & $30.1(3.0)$ & $31.6(4.3)$ & BLS & $34.9 *(4.3)$ & $45.4(5.0)$ & & & & & & \\
\hline
\end{tabular}

Significant differences (Student's $t$-test) between expected $(E)$ and observed $(O)$ values in each mixture are indicated at the right, ${ }^{*} p<$ 0.05, ms marginally significant, $p<0.1$. Acacia caven (A), Bidens pilosa (B), Hiptis mutabilis (H), Lithraea molleoides (L), Stipa eriosthachya $(\mathrm{S})$. 
Table 3 Expected and observed values of mass loss in mixtures with the same level of species richness (standard errors between brackets)

\begin{tabular}{llll}
\hline Mixture & Expected $(E)$ & Observed $(O)$ & Difference $(E-O)$ \\
\hline 2 species & 36.5 & $37.4^{\mathrm{a}}$ & -0.8 \\
& $(1.5)$ & $(1.5)$ & -3.1 \\
3 species & $36.5^{* * *}$ & $39.3^{\mathrm{b}}$ & $(1.3)$ \\
& $(1.0)$ & $40.5^{\mathrm{b}}$ & -4.0 \\
4 species & $36.5^{* * *}$ & $(1.3)$ & -2.5 \\
5 species & $(0.9)$ & $39.0^{\mathrm{ab}}$ & $(3.1)$ \\
\end{tabular}

Different letters at the right of observed values indicated significant differences between mixtures with different species richness (LSD test results, $P<0.05$ ). Significant differences between $E$ and $O$ values (Student's $t$-test) are indicated by asterisks: $* p<0.05$, $* * * p<0.0005$

(from 25 to $66 \%$ fast decomposing species included in the mixture). This last result confirms that decomposition is enhanced when there is a mixture of fast and slow decomposing species, while only slow decomposing species and only fast decomposing species mixtures do not show significant differences between observed and expected values.

Species richness effects in mixtures with constant functional composition

Analysing decomposition rates across mixtures richness, but considering only slow decomposing species (thus, keeping mixture functional composition con- stant); we found that observed values were higher than expected in 4 out of 4 mixtures (Table 2). However, as indicated above, none of these differences were statistically significant. Consistent with this result and although the slope of the regression curve between the observed decomposition rates and slowdecomposing species richness in the mixtures tended to be higher than expected, it was not significantly different (Fig. 1b; $p>0.05$ ). These results, agreeing with the former section, suggest that the effects of mixture richness with constant functional composition are less important than the effects of mixing species with contrasting decomposition. However, our experimental design had a low sample number and the lack
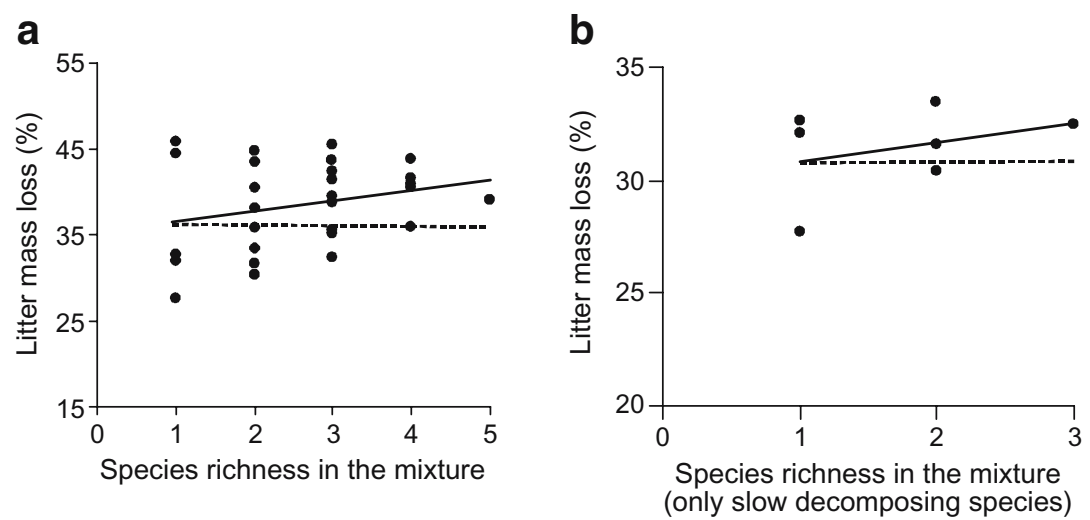

- Observed values

- Observed trendline

-..- Expected trendline

Species richness in the mixture

Fig. 1 Percentage of mass loss in mixtures with increasing species richness decomposed in the field and observed decomposition trend line (black line) considering all mixtures (a) and considering mixtures including only slow-decomposing species (b). The broken line indicate the expected mass loss if

there was no interaction of the litters composing the mixtures (values calculated based on decomposition of the component species incubated under the same conditions in isolation). There were significant differences between the slopes of observed and expected regression $(p=0.03)$ when all mixtures were included 


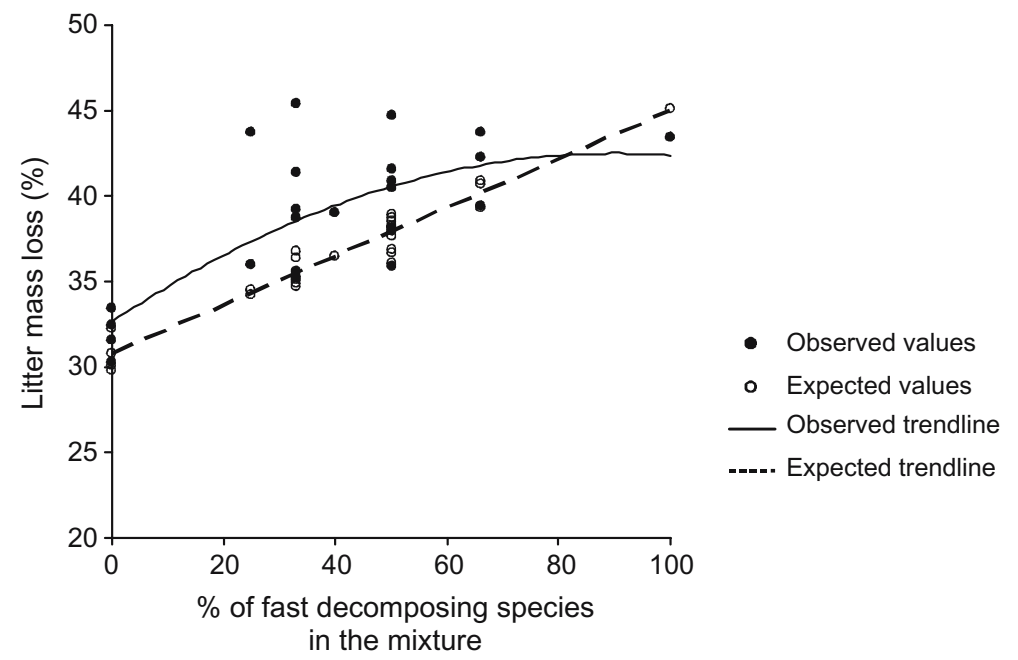

Fig. 2 Percentage of mass loss in mixtures with different composition (composition $=\%$ of fast decomposing species) decomposed in the field and observed decomposition trend line (black line). The broken line (and the empty points) linking $0 \%$ and $100 \%$ of fast decomposing species included in the mixture

of significance may in fact be associated with a shortage of replicates for this treatment.

Initial litter quality and heterogeneity effects on mixtures decomposition

Multiple regressions did not produce a combination of litter quality variables that explained the observed decomposition rate of the mixtures. However, we did find a combination of variables that explained the differences between observed and expected decomposition rates. A model containing litter nitrogen content and CV LCH (sum of non-labile compounds) explained $24 \%$ of the variance in the difference between observed and expected decomposition rates (Table 4). Mixtures with higher mean nitrogen content and a higher heterogeneity in $\mathrm{LCH}$ had the greatest differences between observed and expected decomposition.

Table 4 Model obtained by the backward stepwise regression procedure $(R$ Square $=0.24, F=3.55$, Signif $F=0.05)$

\begin{tabular}{lll}
\hline Variables in the equation & & \\
\hline Variable & $B$ & Significance \\
\hline CV LCH & 18.72 & 0.02 \\
N litter content & 4.57 & 0.05 \\
(constant) & -10.25 & 0.06 \\
\hline
\end{tabular}

indicate the expected mass loss if there was no interaction of the litters composing the mixtures (values calculated based on decomposition of the component species incubated under the same conditions in isolation)

\section{Discussion}

In agreement with previous studies (Wardle et al. 1997, Anderson and Hetherington 1999, Hoorens et al. 2002, Gartner and Cardon 2004), we found that litter mixing affects decomposition rates. When up to 5 species representing different functional types were included, both species richness and functional composition (\% of fast- vs. slow-decomposing species) showed statistically significant non-additive, and in general positive, effects on litter mixture decomposition. The positive effect of mixture richness on decomposition did not disappear, but was much less marked, when considering mixtures of slow-decomposing species only. Although the main driver of decomposition in a mixture is still the average decomposability of the component species (itself largely determined by litter quality), the species interactions in a mixture add a consistent source of variability that is worth considering when predicting the decomposability of a given mixture. We showed that a greater difference between observed and expected decomposition rates was found in mixtures with higher mean nitrogen content and higher heterogeneity in non-labile compounds.

\section{Species richness effects}

We found a positive synergistic effect of species richness on the decomposition of litter mixtures when 
the richness of the mixtures changed from 2 to $3-4$ species. This is in agreement with mixed-litter studies in the field (Hector et al. 2000, Knops et al. 2001), also involving species of different functional types, which found minor but consistent effects of species richness on litter decomposition. Our results are also in agreement with the review from Hättenschwiller et al. (2005) which showed that, across approximately 30 studies, synergistic interactions are the more frequent. However, we are aware that a more complete exploration of mixing effects should include multiple harvests, as different decomposition phases may show opposing responses of litter mixing (McTiernan et al. 1997).

Functional composition effects

Our results also indicate that functional composition can have significant effects on decomposition rates. In particular, decomposition was faster when mixtures included species that showed contrasting decomposition rates in isolation, and, to a lesser extent, when they included only slow-decomposing species. These results present additional evidence to the complementarity hypothesis already mentioned in the introduction: by mixing high- and low-quality litters, easily decomposable resources are available to decomposers, eventually leading to a general high nutrient availability in the mixture and allowing nutrient transfer to the low-quality litter, thus enhancing its decomposability. Other mechanisms, such as priming effects, secondary compound dilution, improved microenvironmental conditions, or effects of specific compound, should not be discarded, as our experimental design do not allow us to make conclusions in those lines.

Litter quality and heterogeneity effects

Although neither the variables measured here nor their combinations were able to predict the actual observed decomposition rates of mixtures, we did find a statistical model explaining part of the differences between observed and expected decomposition. As mentioned above, differences between observed and expected values can be caused by the interactions of the degradation compounds produced by the decomposition process itself (Wardle et al. 1997). Both increased and decreased decomposition rates can be expected based on these interactions, depending on initial litter quality of the constituent species and also on the decomposition stage (Seastedt 1984, McTiernan et al. 1997, Wardle et al. 1997, Hättenschwiller and Vitousek 2000). The model selected here as the best predictor of the differences between observed and expected decomposition rates brings additional evidence for these arguments. Although the proportion of explained variance remains low, this model represents quantitative proof that both the mean nutrient quality of the mixture (in this case, its nitrogen content), and its heterogeneity (in this case, its concentration in nonlabile compounds), can enhance its decomposability. Even if we are still far from a general mechanistic hypothesis, our findings suggest that complementarity mechanisms may be related to both the effect of nitrogen content and that of CV LCH index. Higher nitrogen content may work as a primer, while differences in LCH content between mixtures could be interacting by means of nutrient transfer. New experiments, particularly considering final litter quality, may allow better testing of this and alternative mechanisms.

Together with other studies (e.g. Wardle et al. 1997, Bardgett and Shine 1999, Hector et al. 2000, Anderson and Hetherington 1999, Hoorens et al. 2002, Wardle et al. 2004) our findings indicate that species and functional type richness and identity as well as the chemical composition of litter mixtures are all important factors affecting decomposition of mixed litter.

When taking into consideration our results, however, it must be kept in mind that the work was conducted in a common garden, a much simpler experimental system than a natural litter layer. Additionally it should be noticed that we only focused on mass loss, while nutrient dynamics may not only behave differently, but also give new insights to the mechanisms behind the patterns of mass loss in litter mixtures. Therefore, further experiments exploring the mechanisms of interaction in litter mixtures, particularly in the field and in the long term, are needed to understand this process and to make more accurate predictions about the decomposition and nutrient availability patterns under biodiversity change scenarios. In order to asses the functional significance of biodiversity for decomposition, the characterization of functional traits explaining specific effects of a given species within a community has been considered high research priority (Hättenschwiller et al. 2005). In line with this, the exploration of combination of variables (particularly those related with nutrients and carbon dynamics) to 
explain decomposability patterns in mixtures will provide mechanisms for a generalization of biodiversity effects on decomposition.

Acknowledgements We are grateful to our research team, in particular to A.M. Cingolani for constant support and useful discussions and to D. Abal-Solis for drawing the graphs. Universidad Nacional de Córdoba, CONICET, Agencia Córdoba Ciencia S.E., SECyT-UNC, Inter-American Institute for Global Change Research CRN 2015 (which is supported by the US National Science Foundation-Grant GEO-0452325), and FONCyT supported our research. We thank the Domínguez Family for allowing us to use their property to perform our research. We would further like to thank David Wardle, Fabien Quétier, and two anonymous reviewers for constructive comments on an earlier version of this manuscript.

\section{References}

Anderson JM, Hetherington SL (1999) Temperature, nitrogen availability and mixture effects on the decomposition of heather (Calluna vulgaris (L.) Hull) and bracken (Pteridium aquilinum (L.) Kuhn) litters. Func Ecol 13:116-124

Bardgett RD, Shine A (1999) Linkages between plant litter diversity, soil microbial biomass and ecosystem function in temperate grassland. Soil Biol Biochem 31:317-321

Blair JM, Parmelee RW, Beare MH (1990) Decay rates, nitrogen fluxes and decomposer communities in single and mixed-species foliar litter. Ecol 71:1976-1985

Cadisch G, Giller KE (1997) Driven by nature: plant litter quality and decomposition. CAB International-University Press, Cambridge, p 409

Cornelissen JHC (1996) An experimental comparison of leaf decomposition rates in a wide range of temperate plant species and types. J Ecol 84:573-582

Cornelissen JHC, Pérez Harguindeguy N, Díaz S, Grime JP, Marzano B, Cabido M, Vendramini F, Cerabolini B (1999) Leaf structure and defence control litter decomposition rate across species and life forms in regional floras of two continents. New Phytol 143:191-200

De Fina AL (1992) Aptitud agroclimática de la República Argentina. Academia Nacional de Agronomía y Veterinaria, pp 427

Díaz S, Cabido M (1997) Plant functional types and ecosystem function in relation to global change. J Veg Sci 8:463-474

Draper NR, Smith H (1998) Applied regression analysis, 3rd edn. Wiley, New York

Gartner TB, Cardon ZG (2004) Decomposition dynamics in mixed-species leaf litter a review. Oikos 104:230-246

Goering HK, Van Soest PJ (1970) Forage fiber analyses. Handbook No. 379. Department of Agriculture, USDA, Washington, DC, 20, p 31

Hättenschwiller S, Vitousek PM (2000) The role of polyphenols in terrestrial ecosystem nutrient cycling. Trends Ecol Evol $15: 238-243$

Hättenschwiller S, Tiunov AV, Scheu S (2005) Biodiversity and litter decomposition in terrestrial ecosystems. Ann Rev Ecol Evol Syst 36:191-218
Hector A, Beale AJ, Minns A, Otway SJ, Lawton JH (2000) Consequences of the reduction of plant diversity for litter decomposition: effects through litter quality and microenvironment. Oikos 90:357-371

Hooper DU, Vitousek PM (1997) The effects of plant composition and diversity in ecosystem processes. Science 277:1302-1305

Hooper DU, Chapin FS III, Ewel JJ, Hector A, Inchausti P, Lavorel S, Lawton JH, Lodge DM, Loreau M, Naeem S, Schmid B, Setälä H, Symstad AJ, Vandermeer J, Wardle DA (2005) Effects of biodiversity on ecosystem functioning: a consensus of current knowledge and needs for future research. Ecol Monogr 75:3-35

Hoorens B, Aerts R, Stroetenga M (2002) Litter quality and interactive effects in litter mixtures: more negative interactions under elevated CO2? J Ecol 90:1009-1016

Hoorens B, Aerts R, Stroetenga M (2003) Does initial litter chemistry explain litter mixture effects on decomposition? Oecologia 442:578-586

InfoStat (2002) InfoStat versión 1.1. Grupo InfoStat, FCA, Universidad Nacional de Córdoba, Córdoba, Argentina

Knops JMH, Wedin D, Tilman D (2001) Biodiversity and decomposition in experimental grassland ecosystems. Oecologia 126:429-433

Loreau M, Naeem S, Inchausti P (2002) Biodiversity and ecosystem functioning: synthesis and perspectives. Oxford University Press, Oxford, p 294

McNaughton SJ, Oesterheld M, Frank DA, Williams KJ (1989) Ecosystem- level patterns of primary productivity and herbivory in terrestrial habitats. Nature 341:142-144

McTiernan KB, Ineson P, Coward PA (1997) Respiration and nutrient release from tree leaf litter mixtures. Oikos 78:527-538

Pérez Harguindeguy N, Díaz S, Cornelissen JHC, Vendramini F, Cabido M, Castellanos A (2000) Chemistry and toughness predict leaf litter decomposition rates over a wide spectrum of functional types and taxa in central Argentina. Plant and Soil 218:21-30

Quested HM, Callaghan TV, Cornelissen JHC, Press M (2005) The impact of hemiparasitic plant litter on decomposition: direct, seasonal and litter mixing effects. J Ecol 93:87-98

Seastedt TR (1984) The role of microarthropods in decomposition and mineralization process. Ann Rev Entomol 29:25-46

Smith VC, Bradford MA (2003) Do non-additive effects on decomposition in letter-mix experiments result from differences in resource quality between litters? Oikos 102:235-242

Sokal RR, Rohlf FJ (1995) Biometry - the principles and practice of statistics in biological research, 3rd edn. Freeman, New York, p 887

Vaieretti MV, Pérez Harguindeguy N, Gurvich DE, Cingolani AM, Cabido M (2005) Decomposition dynamics and physicochemical leaf quality of abundant species in a montane woodland in central Argentina. Plant Soil 278:223-234

Wardle DA, Bonner KI, Barker GM (1997) Biodiversity and plant litter: experimental evidence which does not support the view that enhanced species richness improves ecosystem function. Oikos 79:247-258

Wardle DA, Bardgett RD, Klironomos JN, Setälä H, van der Putten WH, Wall DH (2004) Ecological linkages between aboveground and belowground biota. Science 304:1629-163

Zak MR, Cabido M (2002) Spatial patterns of the Chaco vegetation of central Argentina: Integration of remote sensing and phytosociology. App Veg Sci 5:213-226 